Research Journal of Applied Sciences, Engineering and Technology 7(10): 2098-2105, 2014

DOI:10.19026/ajfst.7.503

ISSN: 2040-7459; e-ISSN: 2040-7467

(C) 2014 Maxwell Scientific Publication Corp.

\begin{tabular}{lll}
\hline Submitted: July 4, 2013 & Accepted: July 16, 2013 & Published: March 15, 2014
\end{tabular}

\title{
Research Article \\ Design and Analysis of Single Screw Extruder for Jatropha Seeds Using Finite Element Method
}

\author{
${ }^{1}$ Ali Nurrakhmad Siregar, ${ }^{1}$ Wan Mohd Faizal Wan Mahmod, ${ }^{1}$ Jaharah A. Ghani, \\ ${ }^{1}$ Che Hassan Che Haron and ${ }^{2}$ Muhammad Rizal \\ ${ }^{1}$ Department of Mechanical and Materials Engineering, Faculty of Engineering and Built Environment, \\ Universiti Kebangsaan Malaysia, 43600 UKM Bangi, Selangor, Malaysia \\ ${ }^{2}$ Department of Mechanical Engineering, Faculty of Engineering, Syiah Kuala University, \\ 23111 Darussalam, Banda Aceh, Indonesia
}

\begin{abstract}
Mechanical extraction is commonly used to extract oils from vegetable seeds and a single screw extruder has been successfully reported to separate oil and cake from Jatropha curcas seeds. In this study, a single screw extruder was designed and analyzed using Finite Element Method (FEM) and Computational Fluid Dynamics (CFD). Three different geometrical dimensions of screw extruder were designed and analyzed using FEM and CFD with software ANSYS POLYFLOW to study simulation of the flow and the behavior of Jatropha dough through of a single screw extruder. In a preliminary study, this study focused to simulate the velocity profile and local shear rate indie section with a power law model. The result obtained revealed that three important are as in designing a single screw extruder were gap area (clearance) in the range of $0.5-1.0 \mathrm{~mm}$, chamber area (normal pitch) in the range 17-22 $\mathrm{mm}$ and root area.
\end{abstract}

Keywords: Computational fluid dynamic, finite element method, Jatropha, single screw extruder

\section{INTRODUCTION}

Jatropha is a flowering hedge plant of the Euphorbia family, subfamily Platilobeae with genus more than 70 species. Among them Jatropha curcas, as shown in Fig. 1. Jatropha curcas (J. curcas) or Physic nut is a wild plant that can be grown in all types of soil without need treatment and most of the parts of this plant can be used, such as for medicine, soap making, fertilizer and fuel (biodiesel based) (Achten et al., 2008). Potential as fuel, J. curcas oil content is similar to the oil content of biodiesel, but it must adapt to ASTM D6751 and EN 14214 standards (Silitonga et al., 2013). Usually, two techniques are used to extract $J$. curcas oil i.e., by mechanical extraction and chemical extraction. Mechanical extraction is the most popular technique used due to its easiness, economical and low maintenance. Despite of that, mechanical extraction needs further treatments, such as filtering and degumming. This technique can crush seeds or kernels or a mix of both. In comparison, for chemical extraction, only kernels are used as a material (Achten, 2010). Equipment such as a piston and screw expeller is used to separate oil and cake in mechanical extraction technique.

A screw extruder is usually used in extrusion process such as in the food industry, injection molding

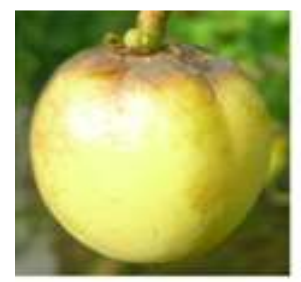

(a)

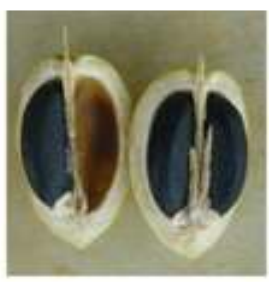

(b)
Fig. 1: (a) Fruit of J. curcas, (b) seed of J. curcas

and plastic production. It is used due to its simple geometry, effective control of product quality and more wider application (Ficarella et al., 2006). Nowadays, this screw is also used in an extraction machine with some equipment modified but still with the same working principle. Karaj and Müller (2011) reported that oil yield of Jatropha of about $89.4 \%$ can be obtained by using a single screw extruder. A single screw extruder has a rotating screw which is rotated inside the barrel as shown in Fig. 2. Seeds are fed into the hopper then it is crushed, conveyed and pushed forward towards the end of the machine as the screw rotates. Furthermore, the oil will come out through the oil outlet while the cake will come out through the nozzle.

\footnotetext{
Corresponding Author: Ali Nurrakhmad Siregar, Department of Mechanical and Materials Engineering, Faculty of Engineering and Built Environment, Universiti Kebangsaan Malaysia, 43600 UKM Bangi, Selangor, Malaysia
}

This work is licensed under a Creative Commons Attribution 4.0 International License (URL: http://creativecommons.org/licenses/by/4.0/) 


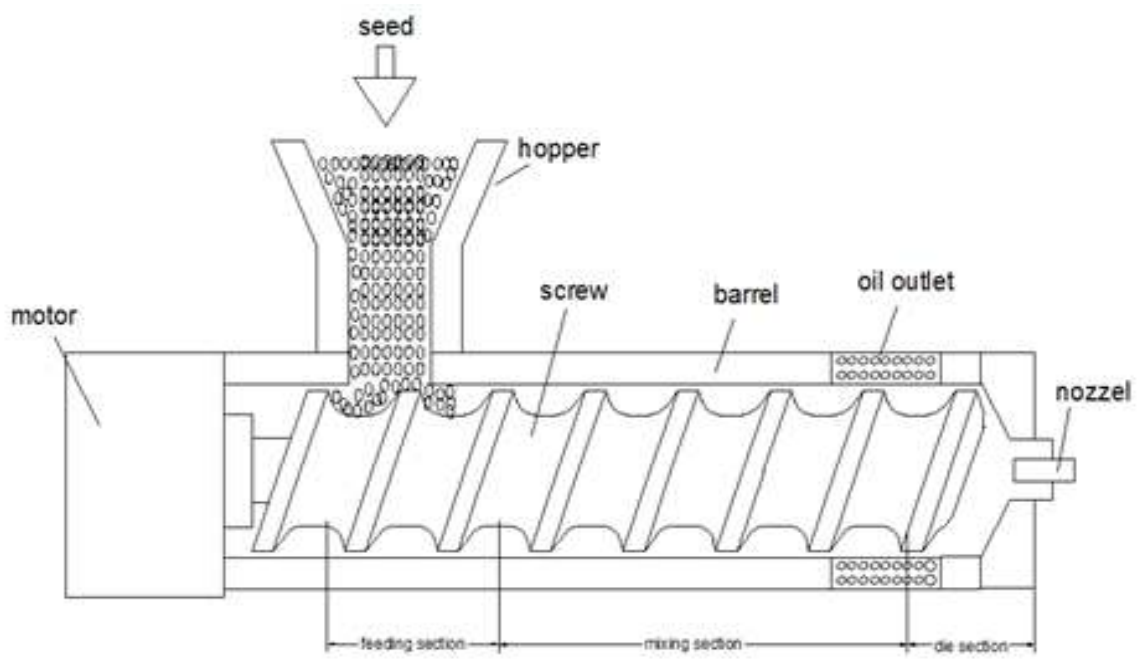

Fig. 2: A single screw extruder

Finite Element Method (FEM) is a numerical method to solve boundary value problems. It is used as an accurate prediction to solve various problems. In addition in this study, a Computational Fluid Dynamics (CFD) is utilized for simulating applications to prediction of fluid flows. Many researchers have designed a single screw extruder using FEM and CFD. Dhanasekharan and Kokini (2003) analyzed a computational method based on numerical simulations to obtain simultaneous scale-up of mixing and heat transfer for wheat dough extrusion. They predicted Residence Time Distribution (RTD) and Specific Mechanical Energy (SME) on design screw geometry. Connelly and Kokini (2007) studied and examined the mixing ability of single and twin screw extruders. They evaluated the dispersive mixing by comparing the mixing index and shear stresses. Jiang and Bi (2009) studied the residence time distribution in a reciprocating single-screw pin-barrel extruder. They concluded that the material viscosity and pins had no effect on the RTD. El-Sadi and Esmail (2005) presented a simulation of complex liquids in micro pump. They predicted that the effective pumping depend on low Reynolds number, high pressure load and high thread depths and it can be investigated by simulation. Finite element method was also used to predict behavior of $J$. curcas under linear compression loading, as reported by Petru et al. (2012). They demonstrated compression using FEM simulation to study mechanical properties of ripe, unripe and over-ripe $J$. curcas

ANSYS POLYFLOW is a finite-element Computational Fluid Dynamics (CFD) program designed to solve flow problems in polymer, injection molding, food rheology, glass-work furnaces and chemically reacting flows where material is identified as viscous and viscoelastic (ANSYS, 2011). Its simulation was used to investigate flow and behavior of the fluid in the single-screw extruder to be a Newtonian fluid which the viscosity is constant. It can be used to analyze many problems, for example shear rate, specific mechanical energy, residence time distribution, temperature distribution and velocity profile. This study proposes a CFD with a power law model to simulate the velocity profile and the local shear rate of J. curcas dough in die section on three designs geometrical dimensions of the screw.

\section{MATERIALS AND METHODS}

Recently, the computer can be used to solve fluid flow problems. In this study the program is based on the flow chart as shown in Fig. 3.

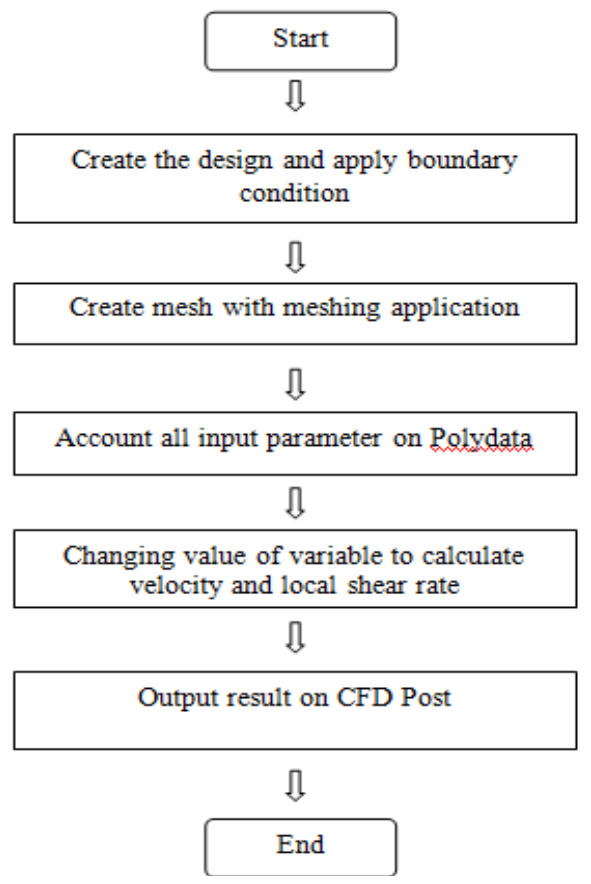

Fig. 3: Flowchart of the simulation process 
Res. J. Appl. Sci. Eng. Technol., 7(10): 2098-2105, 2014

Table 1: Geometrical dimension of screw

\begin{tabular}{lllllllll}
\hline Dimension & $\mathrm{L}(\mathrm{mm})$ & $\mathrm{d}(\mathrm{mm})$ & $\mathrm{D}(\mathrm{mm})$ & $\mathrm{Cl}(\mathrm{mm})$ & $\mathrm{H}\left({ }^{\circ}\right)$ & $\mathrm{SF}(\mathrm{mm})$ & $\mathrm{NP}(\mathrm{mm})$ & $\mathrm{P}(\mathrm{mm})$ \\
\hline Screw 1 & 236 & 40 & 60 & 0.5 & 20 & 3 & 27 & 30 \\
Screw 2 & 236 & 40 & 60 & 0.5 & 20 & 3 & 22 & 17 \\
Screw 3 & 236 & 40 & 60 & 0.5 & 20 & 3 & 20 \\
\hline
\end{tabular}

In order to investigate various velocity profiles and local shear rate in die section, three designs of the screw was created using SOLID WORK 2008 and imported by POLYFLOW to design the modeler as shown in Fig. 4. The constant dimensions defined for the screw design were Length (L), internal diameter (d), external Diameter (D), Clearance (Cl), Helix angel (H) and Screw Flight (SF). Whereas, the Normal Pitch (NP) and Pitch $(\mathrm{P})$ were varied. The pitch was varied by 5 $\mathrm{mm}$ as often used by several researchers as given in Table 1. Basic geometry of the screw is shown in Fig. 5.

The boundary condition is space between the wall of the screw and the inner surface of the barrel as shown in Fig. 6. Further, Ansys meshing application is used to create mesh elementson the screw and barrel. The Boundary divides tasks with sub task 1 and sub task 2.

The conditions at the boundaries are:

- Boundary 1: CE, input

- Boundary 2: EF, Wall of the inner barrel

- Boundary 3: DF, Output

- Boundary 4: $\mathrm{CD}$, wall of the screw

Finite Element Method (FEM) simulations with CFD software ANSYS Poly flow 14.0 solves for conservation of mass and momentum (ANSYS, 2011):

$$
\begin{aligned}
& \nabla . v=0 \\
& \nabla . T+f-\nabla p=\rho \frac{D v}{D t}
\end{aligned}
$$

where,

$v=$ The velocity vector

$T=$ The stress tensor

$f=$ Volume force

$p=$ The pressure

$\rho=$ The fluid density

$t=$ Time

The Power law is a type of generalized Newtonian fluid. This model used to calculate the viscosity of fluid depends upon the shear rate according to the following equation (ANSYS, 2011):

$$
\eta=J(\lambda \dot{t})^{n-1}
$$

where,

$J=$ The consistency factor

$\lambda \dot{t}=$ The natural time

$n=$ Power law index

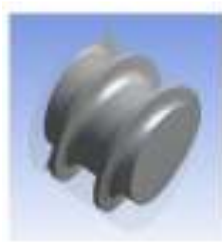

(a)

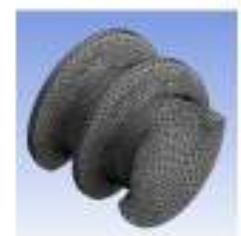

(b)

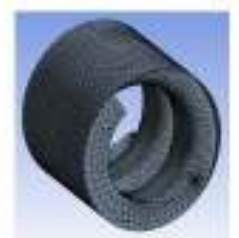

(c)
Fig. 4: (a) Design screw in design modeler, (b) meshing of screw, (c) meshing of barrel

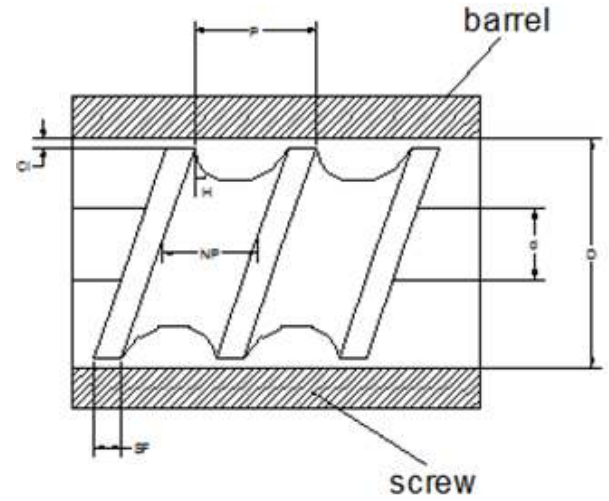

Fig. 5: Geometry of screw

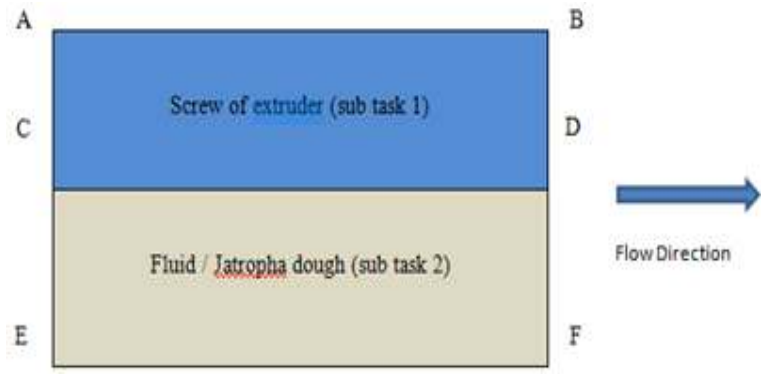

Fig. 6: Boundary condition

$$
T=2 \eta D
$$

And:

$$
T=2 J(\lambda \dot{t})^{n-1} D
$$

where,

$\mathrm{D}=$ The rate of strain tensor with the shear rates $(\dot{\gamma})$

$T=$ The stress tensor

Finally, the velocity magnitude can be calculated as:

$$
2 J(\lambda \dot{t})^{n-1} D+f-\nabla p=\rho \frac{D v}{D t}
$$


Table 2: Input parameter in simulation process

\begin{tabular}{|c|c|c|c|}
\hline Parameter & & & Reference \\
\hline Screw speed (rad/sec) & & $7.33-36.66$ & Karaj and Müller (2011) \\
\hline Mass flow rate $(\mathrm{gr} / \mathrm{sec})$ & & 30 & \\
\hline Density of $J$. curcas $\left(\mathrm{g} / \mathrm{mm}^{3}\right)$ & & 0.278 & Pradhan et al. ( 2009) \\
\hline Viscosity $(\mathrm{cm} / \mathrm{sec})$ & Consistency factor & $2500 \mathrm{~Pa} \mathrm{~s}^{\mathrm{n}}$ & Dhanasekharan et al. (1999) \\
\hline & Natural time & $0.52 \mathrm{sec}$ & Dhanasekharan et al. (1999) \\
\hline & Power law index & 0.8 & Dhanasekharan et al. (1999) \\
\hline
\end{tabular}

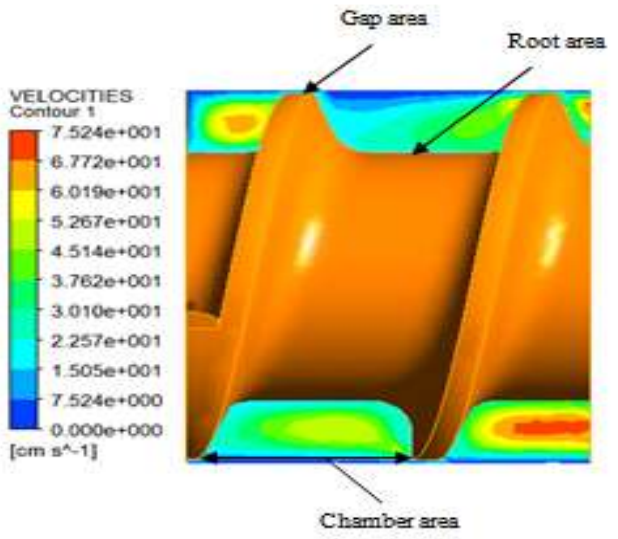

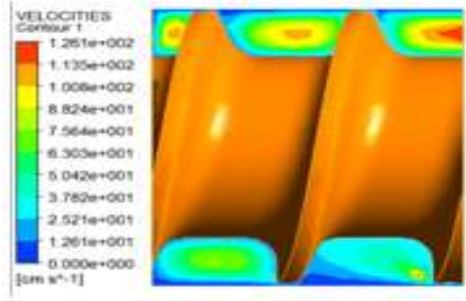

(b) Screw 2 (a) Screw 1

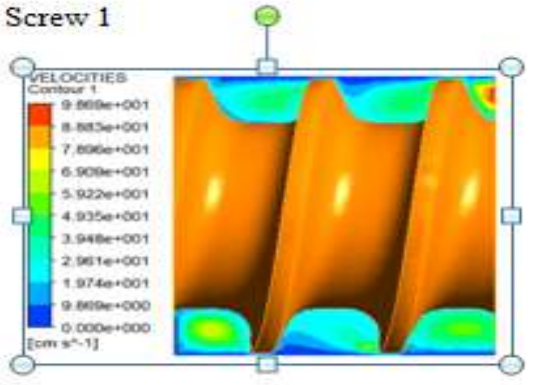

(c) Screw 3

Fig. 7: Prediction of velocity profile at screw speed $=7.333 \mathrm{rad} / \mathrm{sec}$

And, the local shear rate is defined as:

$$
\dot{\gamma}=\sqrt{2(D)^{2}}
$$

To simulate the flow and the behavior of the fluid, the input parameter is as shown in Table 2. These dates were obtained from previous researchers as indicated.

\section{RESULTS AND DISCUSSION}

The steady state problem was solved using CFD Post Solver after calculating the POLYDATA. The concept of velocity and local shear rate describes the flow was within the small gap between two concentric cylinders, one rotating at a constant speed and the other one was stationary. The process begins when the screw was rotated in the barrel so that the Jatropha seed will split and meshed to become the Jatropha dough. Later, the material was moving from one chamber to the next, due to the drag force exerted from the screw rotation on the $\mathrm{z}$-direction. Which then, it led to differences in the velocity magnitude and local shear rate. Simulation results were used for modified several variables to find the best expected results. The contour was based on the color code, with blue as the lowest to red as the highest velocity and local shear rate.

Effect of pitch screw: The velocity profile and local shear rate inside a screw extruder were the important factors since they can be used to determine the effectiveness of the screw extruder. Figure 7 shows the prediction of velocity profile at screw speed of 7.333 $\mathrm{rad} / \mathrm{sec}$. Figure 7 revealed that there are some areas that can be studied to predict the flow and behavior of material in a single screw extruder with different sizes of pitch screw:

- Gap area (clearance): This area is the distance between the inner surface of the barrel and the surface of screw flight. The code color of blue indicates $0 \mathrm{~cm} / \mathrm{sec}$. Meaningless material passing through this area and can be ignored. This area is 
often called the zero velocity area. Therefore, the size of the gap should be $0.5-1.0 \mathrm{~mm}$, if the gap area is too large, the material is difficult to push forward but if it is too small, screw flight will rub against with the surface of the inner barrel lead to overheating.

- Chamber area (normal pitch): This area is a distance between blades, both above and below. This is the center of circulation, which the material is transferred from one chamber to the other chamber. Furthermore, it will get the pressure force from the die section, therefore high pressure is required to push the material forward. The figure shows that the highest velocity (red color) in this area, which indicates, the Jatropha dough has maximum speed on the barrel wall. In the design screw 1, the normal pitch was $27 \mathrm{~mm}$. The normal pitch spacing was too wide that caused not enough pressure to force the material flow. Thus the size of this area is suggested in the range of $17-22 \mathrm{~mm}$.

- Road area: This area is surface of body of the screw. They show that the code color is sky blue; there was also less circulation of material in the axial velocity with approximately $15-35 \mathrm{~cm} / \mathrm{sec}$. Figure 8 shows prediction of local shear rate at screw speed $7.333 \mathrm{rad} / \mathrm{sec}$. They show that gap area and around the screw flight is the highest shear rate location (red color). Whereas, the shear rate can be ignored in other areas.

Effect of screw speed: Figure 9 shows prediction of velocity profile at screw speed of $9.429 \mathrm{rad} / \mathrm{sec}$. When comparing with Fig. 7, it can be explained that by increasing the screw speed from 7.333 to $9.429 \mathrm{rad} / \mathrm{sec}$, the velocity increases from 75.24 to $96.75 \mathrm{~cm} / \mathrm{sec}$ at design screw $1,126.1$ to $162.1 \mathrm{~cm} / \mathrm{sec}$ at design screw 2 and 98.69 to 126.9 at design screw 3, respectively. However, by increasing the screw speed, it does not cause the change of the contour map. Therefore the flow and behavior of material are still same regardless of speed screw. But the local shear rate is increasing by increasing of screw speed from 7.333 to $9.429 \mathrm{rad} / \mathrm{sec}$, which caused the local shear rate to increase from 3314 to $4262 / \mathrm{sec}$ at design screw 1,13950 to $17940 / \mathrm{sec}$ at design screw 2 and 3621 to $4656 / \mathrm{sec}$ at design screw 3, respectively as shown in Fig. 8 and 10.

Table 3 shows changes of screw rotating speed will increase the velocity and local shear rate. The lowest rotation of the screw at 7,333 rad/sec resulted in; 75.21 $\mathrm{cm} / \mathrm{sec}$ on screw design $1,126 \mathrm{~cm} / \mathrm{sec}$ on screw design 2 and $98.6 \mathrm{~cm} / \mathrm{sec}$ on screw design 3 , respectively.

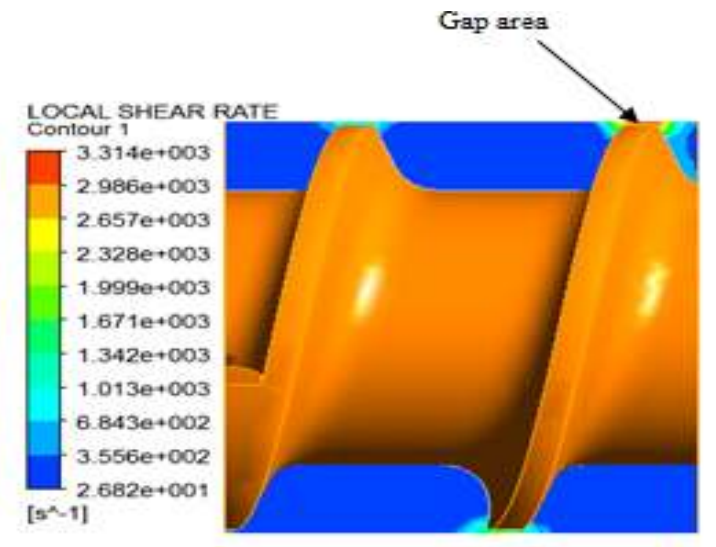

(a) Screw 1

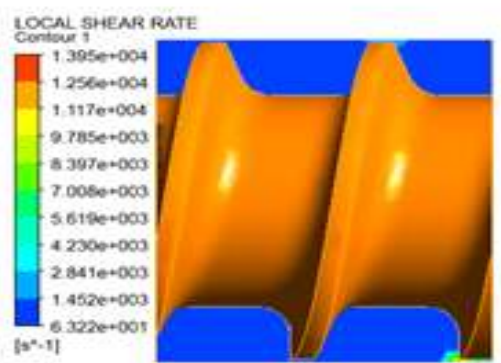

(b) Screw 2

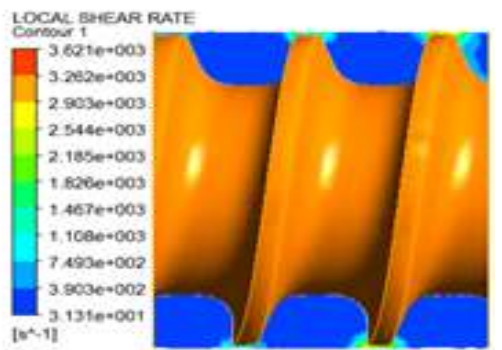

(c) Screw 3

Fig. 8: Prediction of local shear rate at screw speed $=7.333 \mathrm{rad} / \mathrm{sec}$ 


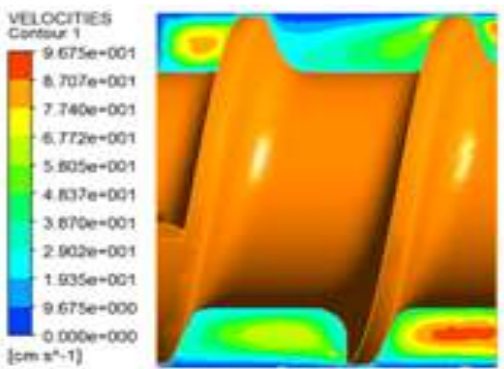

(a) Screw 1

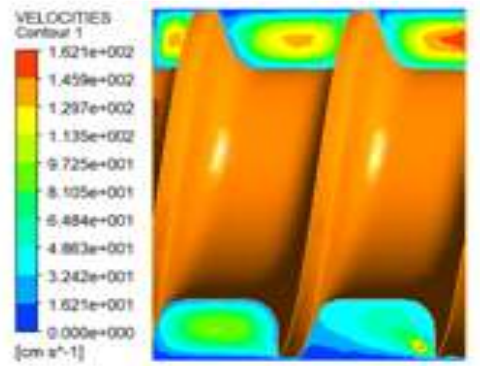

(b) Screw 2

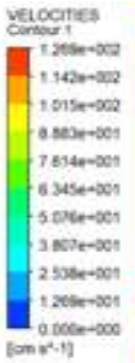

Fig. 9: Prediction velocity profile at screw speed $=9.429 \mathrm{rad} / \mathrm{sec}$

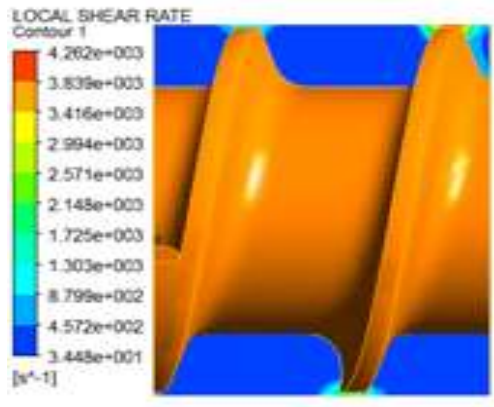

(a) Screw 1

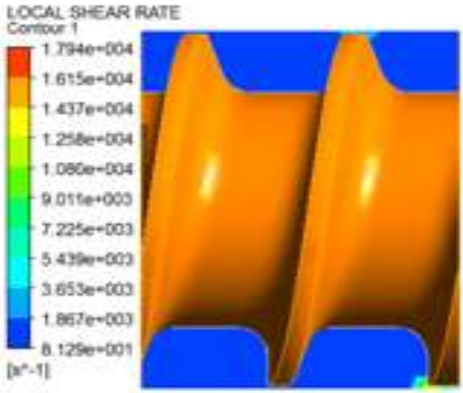

(b) Screw 2 (c) Screw 3

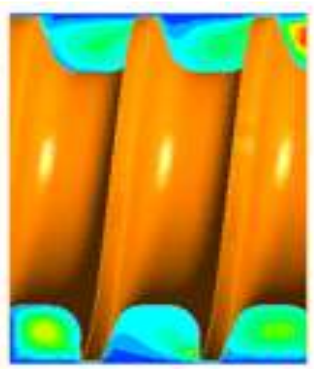

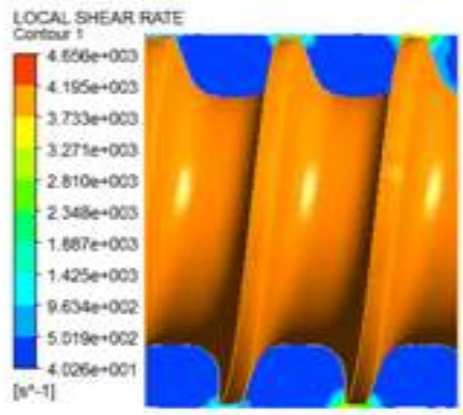

(c) Screw 3

Fig. 10: Prediction local shear rate at screw speed $=9.429 \mathrm{rad} / \mathrm{sec}$

Table 3: Effect screw speed on velocity magnitude and local shear rate

\begin{tabular}{|c|c|c|c|c|c|c|}
\hline \multirow[b]{2}{*}{$\begin{array}{l}\text { Screw speed } \\
(\mathrm{rad} / \mathrm{sec})\end{array}$} & \multicolumn{3}{|c|}{ Velocity magnitude $(\mathrm{cm} / \mathrm{sec})$} & \multicolumn{3}{|c|}{ Local shear rate $(/ \mathrm{sec})$} \\
\hline & Screw 1 & Screw 2 & Screw 3 & Screw 1 & Screw 2 & Screw 3 \\
\hline 7.333 & 75.24 & 126 & 98.69 & 3314 & 13950 & 3621 \\
\hline 9.429 & 96.75 & 162 & 126.90 & 4262 & 17940 & 4656 \\
\hline 11.524 & 118.20 & 198 & 155 & 5210 & 21930 & 5691 \\
\hline 13.619 & 139.70 & 234 & 183.20 & 6158 & 25920 & 6726 \\
\hline 15.715 & 161.20 & 270 & 211.40 & 7106 & 29910 & 7761 \\
\hline 17.810 & 182.70 & 306 & 239.60 & 8054 & 33900 & 8796 \\
\hline 19.905 & 204.20 & 342 & 267.80 & 9002 & 37890 & 9831 \\
\hline 22 & 225.70 & 378 & 296 & 9950 & 41880 & 10866 \\
\hline 24.096 & 247.20 & 414 & 324.20 & 10898 & 45870 & 11901 \\
\hline 26.191 & 268.70 & 450 & 352.40 & 11846 & 49860 & 12936 \\
\hline 28.287 & 290.20 & 486 & 380.60 & 12794 & 53850 & 13971 \\
\hline 30.382 & 311.70 & 522 & 408.80 & 13742 & 57840 & 15006 \\
\hline 32.477 & 333.20 & 558 & 437 & 14690 & 61830 & 16041 \\
\hline 34.573 & 354.70 & 594 & 465.20 & 15638 & 65820 & 17076 \\
\hline 36.668 & 376.20 & 630 & 493.30 & 16586 & 69810 & 18111 \\
\hline
\end{tabular}

Furthermore, the highest velocity is obtained at screw speed of $36.668 \mathrm{rad} / \mathrm{sec}$. It's expected that, when the screw rotates faster i.e., at high rotating speed, will cause smooth flow and the materials move to the die gate more quickly. But it does not mean that the more oil yield can be obtained, because it requires to adjust the size of the nozzle. Furthermore, the lowest rotation of the screw at $7.333 \mathrm{rad} / \mathrm{sec}$ resulted in three different of local shear rate; $3314 / \mathrm{sec}$ on screw design 1 , 13950/sec on design 2 and $3621 /$ sec on design 3 , respectively. Figure 11 shows the difference in the velocity of each design. Whereas Fig. 12 shows the difference in the local shear rate of each design.

Effect of mass flow rate: Figure 13 shows the prediction of velocity and local shear rate at mass flow rate $30 \mathrm{~g} / \mathrm{sec}$ and mass flow rate $100 \mathrm{~g} / \mathrm{sec}$ with same screw speed of $7.333 \mathrm{rad} / \mathrm{sec}$. This figure compares the 
Res. J. Appl. Sci. Eng. Technol., 7(10): 2098-2105, 2014

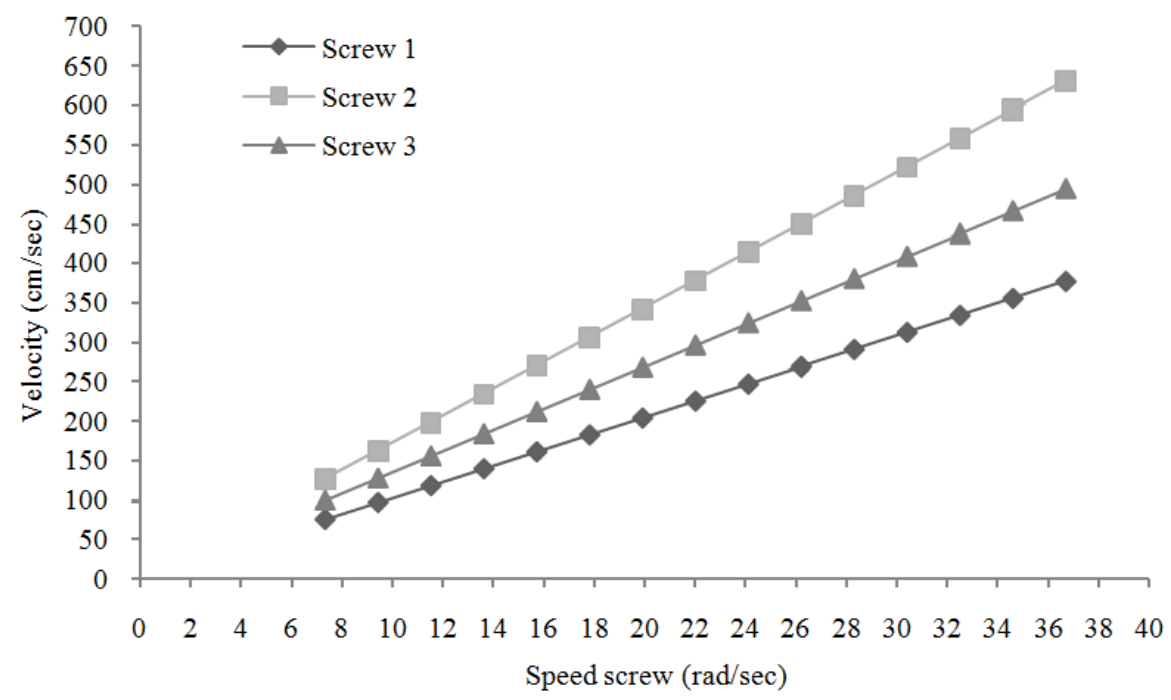

Fig. 11: Screw speed vs. velocity magnitude

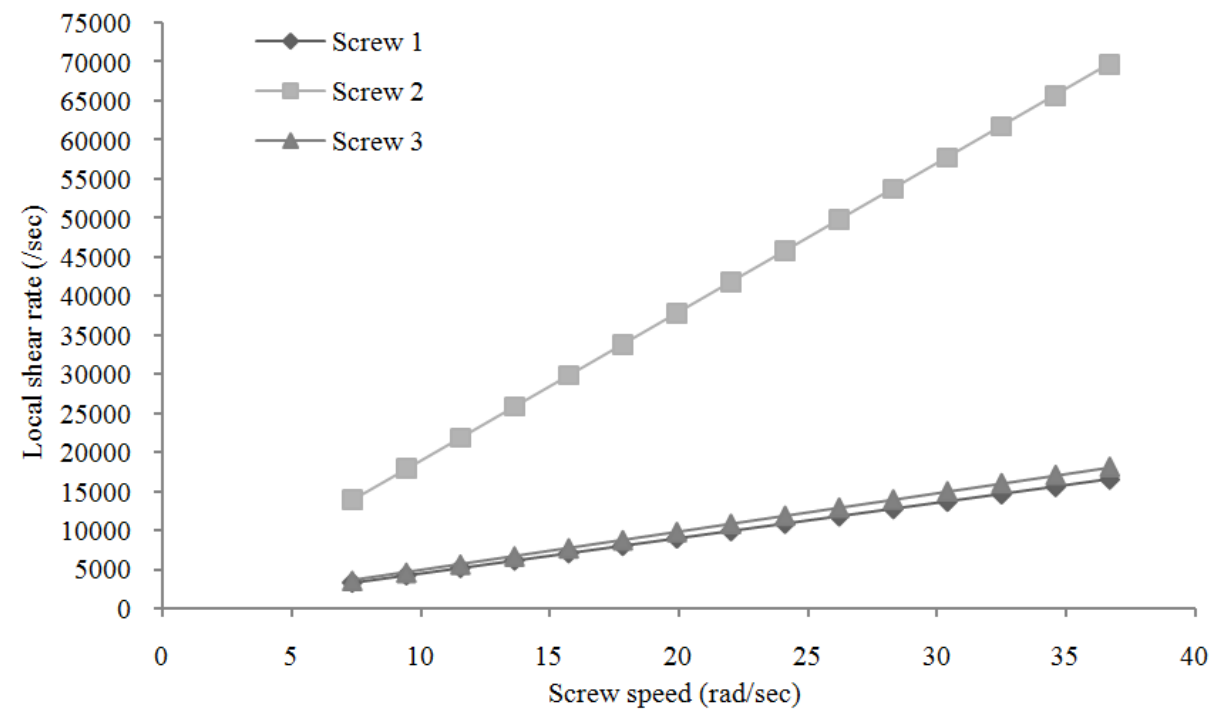

Fig. 12: Screw speed vs. local shear rate

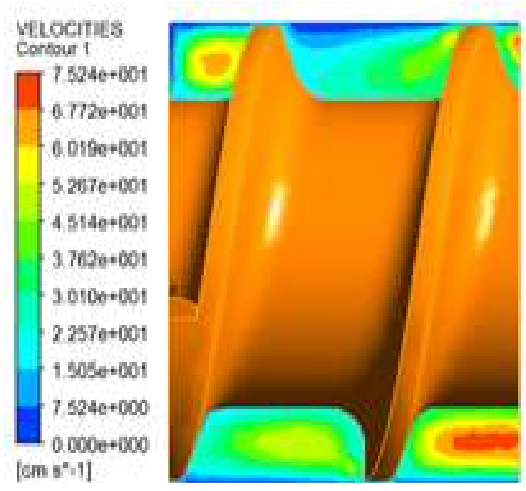

(a)

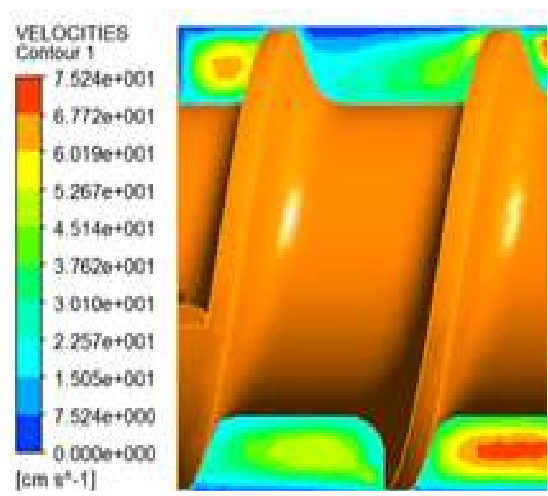

(b)

Fig. 13: Prediction of velocity magnitude and local shear rate at screw speed $=7.333 \mathrm{rad} / \mathrm{sec}$ on screw 1 , (a) mass flow rate $=30$ $\mathrm{g} / \mathrm{sec}$, (b) mass flow rate $=100 \mathrm{~g} / \mathrm{sec}$ 
velocity and local shear rate with different mass flow rate but with the same screw speed. Clearly shown from this figure, increasing the mass flow rate will not affect the velocity and local shear rate. In addition, increasing the mass flow rate will slightly change the contour of the map.

\section{CONCLUSION}

Based on the simulation results, it can be concluded that:

- Finite element method using ANSYS POLYFLOW is suitable to simulate the flow and behavior of Jatropha dough in a single screw extruder.

- The velocity and local shear rate depend on the dimension of the screw (length, diameter, pitch, normal pitch, clearance, he lix angel and screw flight), physical properties of materials (density) and input parameter (screw speed, mass flow rate and viscosity).

- Increasing screw speed caused the increase in velocity and local shear rate. Whilst, the increasing mass flow rate will not give significant effect to the velocity and local shear rate.

- Three important areas in a single screw extruder are gap area (clearance) in the range of 0.5-1.0 $\mathrm{mm}$, chamber area (normal pitch) in the range 17$22 \mathrm{~mm}$ and root area.

\section{ACKNOWLEDGMENT}

The research is financed by Universiti Kebangsaan Malaysia for Grant No. UKM-DLP-2011-057. The authors would like to thank the Government of Malaysia and the university authorities for their financial support.

\section{REFERENCES}

Achten, W., 2010. Sustainability evaluation of biodiesel from Jatropha curcas L. Ph.D. Thesis, Katholieke University, Leuven, Belgium, pp: 176.

Achten,W.M.J., L. Verchot, Y.J. Franken, E. Mathijs, V.P. Singh and R. Aerts, 2008. Jatrophabio-diesel product ion and use. Biomass Bioenerg., 32: 1063-1084.
ANSYS, I., 2011. ANSYS Polyflow User's Guide. ANSYS Inc., Canonsburg, PA.

Connelly, R.K. and J.L. Kokini, 2007. Examination of the mixing ability of single and twin screw mixers using 2D finite element method simulation with particle tracking. J. Food Eng., 79: 956-969.

Dhanasekharan, K.M. and J.L. Kokini, 2003. Design and scaling of wheat dough extrusion by numerical simulation of flow and heat transfer. J. Food Eng., 60: 421-430.

Dhanasekharan, M., H. Huang and J.L. Kokini, 1999. Comparison of the observed rhological properties of hard wheat flour dough with the predictions of the Giesekus-Leonov, White-Metzner and PhanThien Tanner models. J. Texture Stud., 30: 603-623.

El-Sadi, H. and N. Esmail, 2005. Simulation of complex liquids in micropump. Microelectr. J., 36: 657-666.

Ficarella, A., M. Milanese and D. Laforgia, 2006. Numerical study of the extrusion process in cereals production: Part I. Fluid-dynamic analysis of the extrusion system. J. Food Eng., 73: 103-111.

Jiang, B. and C. Bi, 2009. Study of residence time distribution in a reciprocating single screw pinbarrel extruder. J. Mater. Process. Tech., 209: 4147-4153.

Karaj, S. and J. Müller, 2011. Optimizing mechanical oil extraction of Jatropha curcas L. seeds with respect to press capacity, oil recovery and energy efficiency. Ind. Crops Prod., 34: 1010-1016.

Petru, M., O. Novak, D. Hera and S. Simanjuntak, 2012. Finite element method model of the mechanical behaviour of Jatropha curcas L. seed under compression loading. Biosyst. Eng., 111: 412-421.

Pradhan, R.C., S.N. Naik, N. Bhatnagar and V.K. Vijay, 2009. Moisture-dependent physical properties of jatropha fruit. Ind. Crops Prod., 29: 341-347.

Silitonga, A.S., H.H. Masjuki, T.M.I. Mahlia, H.C. Ong, A.E. Atabani and W.T. Chong, 2013. A global comparative review of biodiesel production from Jatropha curcas using different homogeneous acid and alkaline catalysts: Study of physical and chemical properties. Renew. Sust. Energ. Rev., 24: 514-533. 